\title{
An Attempt to Classify Gram-Stained Vaginal Smears with a Nugent Score of 4 into Four Bacterial Morphotypes at First Prenatal Visit
}

\author{
Satoshi Shimano ${ }^{1,2}$, Atsushi Yasuda3 ${ }^{3}$ Takashi Ogaya ${ }^{3}$, Sachiko Miura3 ${ }^{3}$, Hideaki Negishi4, \\ Masahiro Mizunuma4, Tsuyoshi Saito ${ }^{2}$ \\ ${ }^{1}$ Department of Obstetrics and Gynecology Nakashibetsu Municipal Hospital, Nakashibetsu, Hokkaido, Japan \\ ${ }^{2}$ Department of Obstetrics and Gynecology Sapporo Medical University School of Medicine, Sapporo, Hokkaido, Japan \\ ${ }^{3}$ Clinical laboratory, Kitami Red Cross Hospital, Kitami, Hokkaido, Japan \\ ${ }^{4}$ Department of Obstetrics and Gynecology Kitami Red Cross Hospital, Kitami, Hokkaido, Japan \\ Email: *shima722@beach.ocn.ne.jp, a_yasuda@kitami.jrc.or.jp,t_ogaya@kitami.jrc.or.jp,s_miura@kitami.jrc.or.jp, \\ h_negishi@kitami.jrc.or.jp,m_mizunuma@kitami.jrc.or.jp,tsaito@sapmed.ac.jp
}

How to cite this paper: Shimano, S., Yasuda, A., Ogaya, T., Miura, S., Negishi, H., Mizunuma, M. and Saito, T. (2020) An Attempt to Classify Gram-Stained Vaginal Smears with a Nugent Score of 4 into Four Bacterial Morphotypes at First Prenatal Visit. Advances in Microbiology, 10, 60-71. https://doi.org/10.4236/aim.2020.103006

Received: January 29, 2020

Accepted: March 2, 2020

Published: March 5, 2020

Copyright $\odot 2020$ by author(s) and Scientific Research Publishing Inc. This work is licensed under the Creative Commons Attribution International License (CC BY 4.0).

http://creativecommons.org/licenses/by/4.0/

\begin{abstract}
It is controversial whether universal screening for bacterial vaginosis (BV) should be done in the early stages of pregnancy in order to prevent preterm birth. In particular, whether the intermediate vaginal flora type should be included in the group to be treated for BV. This vaginal smear type is a mixture of Lactobacillus and Gardnerella or Bacteroides spp. We examined three vaginal flora types, excluding the mixed-type, with a Nugent Score of 4 and evaluated their significance in achieving term delivery. The subjects were pregnant women who were examined at our Hospital between June 2009 and December 2010. Their vaginal swabs were taken at their first prenatal visit and were studied by Gram staining. The resulting Nugent Score 4 organisms were further classified into the following four types: mixed-type, gram-positive cocci type, Bifidobacterium type, and non-bacterial type. The clinical courses for all the types except "mixed-type" were followed-up. Among the 566 pregnant women, 58 (10.2\%) had a Nugent Score of 4 . There were 38 cases of mixed-type (65.5\%), 3 cases of gram-positive cocci type (5.2\%), 10 cases of Bifidobacterium type (17.2\%), and 7 cases of non-bacterial type $(12.1 \%)$. The three women with the gram-positive cocci type attained successful term delivery despite two of them experiencing GBS infection and requiring treatment with penicillin and tocolytics. Among the 10 cases of $B i$ fidobacterium type, 5 cases were term delivery with no therapy, 3 cases were term delivery with metronidazole treatment and 2 cases were preterm birth with maternal complications. Among the 7 cases of non-bacterial type, 6 cas-
\end{abstract}


es were diagnosed with preterm PROM, and 5 of them resulted in preterm birth despite prophylactic antibiotic therapy. Classification of smears with a Nugent score of 4 into four bacterial morphotypes may be effective, for required treatment may vary depending on the morphotype.

\section{Keywords}

Bacterial Vaginosis (BV), Nugent Score 4, Pregnancy, GBS (Group B Streptococcus), Bifidobacterium spp.

\section{Introduction}

Until now, it was controversial whether universal screening for bacterial vaginosis (BV) should be done in the early stages of pregnancy followed by eventual treatment of BV in order to prevent preterm birth due to ascending bacterial infection into the uterus from the vagina [1] [2].

Two reviews, one negative [1] and one positive [2], have been published in the Cochrane Database of Systematic Reviews on the prevention of preterm birth by treating BV. In the negative review published in 2013 [1], the use of antibiotics did not reduce the risk of preterm birth before 37 weeks in a subgroup of pregnant women with $\mathrm{BV}$, which excluded those with intermediate vaginal flora. However, in a subgroup of women with intermediate flora or BV, the use of antibiotics was associated with a significant reduction in preterm birth before 37 weeks [3] [4]. These results suggest that treating pregnant women with an intermediate vaginal flora along with those with BV in early gestation reduces the risk of preterm birth. The intermediate vaginal flora type here likely refers to a mixture of Lactobacillus and Gardnerella or Bacteroides spp.

We have studied the Gram-stained vaginal smears from pregnant women since 1991 [5] [6] [7] and during that time we began to question whether women with an intermediate vaginal flora, especially a Nugent Score of 4 , should all be treated regardless of the types of bacteria observed in their vaginal smear. According to the Nugent scoring system, gram-positive cocci were removed from the diagnostic morphotype system because that group had the poorest agreement concerning the detection of morphotype both within and between centers [8]. In the end, we reached the conclusion that the gram-positive cocci were easily detected in vaginal smears of Nugent score 4 bacteria when they were present alone. However, when this type of bacteria was present mixed with gram-positive or -negative rods such as Gardnerella vaginalis or Bacteroides spp., this bacterial morphotype was not detected easily.

Similarly, if Bifidobacterium spp. were present alone, they were easily detected in a vaginal smear and diagnosed as Nugent score 4 . It is a question whether the Bifidobacterium spp. should be included in the treatment of BV in order to prevent preterm birth. 
A Nugent score of 4 was assigned to the smears from pregnant women who had experienced preterm PROM (Premature rupture of membrane) and were transferred to our hospital from other prenatal units because there were no bacteria on their vaginal smear slides. Supposedly, the bacteria had been washed out by amniotic fluid during the preterm PROM. We have now further investigated the pregnancy course and outcome for women with vaginal smears of Nugent Score 4, except for those with mixed bacterial types.

\section{Materials and Methods}

\subsection{Patients}

The subjects were 566 pregnant women who visited the Kitami Red Cross Hospital $(\mathrm{KRCH})$ in Hokkaido. Japan, to receive prenatal care and give birth or who were transferred to the $\mathrm{KRCH}$ for the treatment of prenatal complications requring prenatal intensive care between June 2009 and December 2010.

Their average age was $30.7 \pm 4.9$ years (mean \pm SD). Their gestational weeks were: $<12 \mathrm{GW}$ in 288 cases, $12 \mathrm{GW} \leq-<16 \mathrm{GW}$ in 33 cases, $16 \mathrm{GW} \leq-<20 \mathrm{GW}$ in 44 cases, $20 \mathrm{GW} \leq-<24 \mathrm{GW}$ in 15 cases, $24 \mathrm{GW} \leq-<28 \mathrm{GW}$ in 21 cases, 28 $\mathrm{GW} \leq-<32 \mathrm{GW}$ in 50 cases, $32 \mathrm{GW} \leq-<36 \mathrm{GW}$ in 92 cases, $36 \mathrm{GW} \leq-<40$ $\mathrm{GW}$ in 23 cases. $\mathrm{KRCH}$ is the third prenatal hospital in Japan that admits pregnant women with no risk as well as those with high risk.

\subsection{Sample Collections and Diagnosis of BV}

Vaginal swabs and medical histories were obtained from the women at their first prenatal visit. A clean non-lubricated speculum was placed in the vagina. A sterile cotton transfer swab (by COPAN ITALIA S. p. A.) [9] was used to obtain the vaginal swabs from the lateral wall. The cotton swab was rolled on glass slides, and the specimen was stained by the Gram stain according to the Bartholomew and Mittwer method. Each Gram-stained smear was observed under a microscope at a magnification of X1000, and BV was diagnosed according to Nugent scoring system [8].

\subsection{Subclassification of Nugent Score of 4}

A Nugent score of 4 was classified into the following four types: mixed-type of Lactobacillus and Gardnerella or Bacteroides spp. (Figure 1), gram-positive cocci type (Figure 2), Bifidobacterium type (Figure 3), and non-bacterial type in which the smear consists of epithelial cells (Figure 4). These bacteria were identified by culturing in an atmosphere of $7 \%$ carbon dioxide and were not identified by anaerobic culturing. Bifidobacterium spp. in Figure 3 were identified by 16S ribosomal RNA gene sequencing (The methods are shown in Figure 5 and the results in Figure 6) [10].

\subsection{Study Area}

Kitami City is located in the eastern part of Hokkaido, the northern island of 


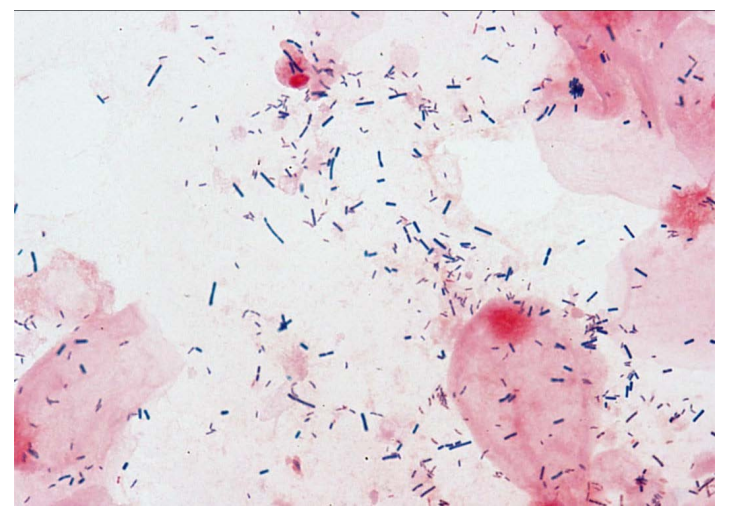

Figure 1. Gram-stained vaginal smear from a pregnant woman with intermediate vaginal flora (Nugent score of 4). This smear is called "mixed-type" as it consists of 4+ Lactobacillus morphotypes and 4+ Gardnerella spp. or Bacteroides spp. morphotypes.

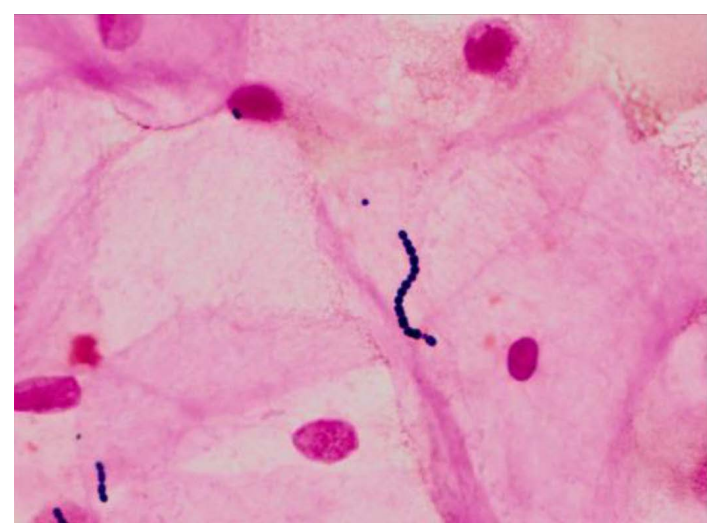

Figure 2. Gram-stained vaginal smear from the pregnant woman of case 1 (shown in Table 1). Gram-positive cocci were identified at the first prenatal visit at 10 weeks of gestation. This smear is called "gram-positive cocci type".

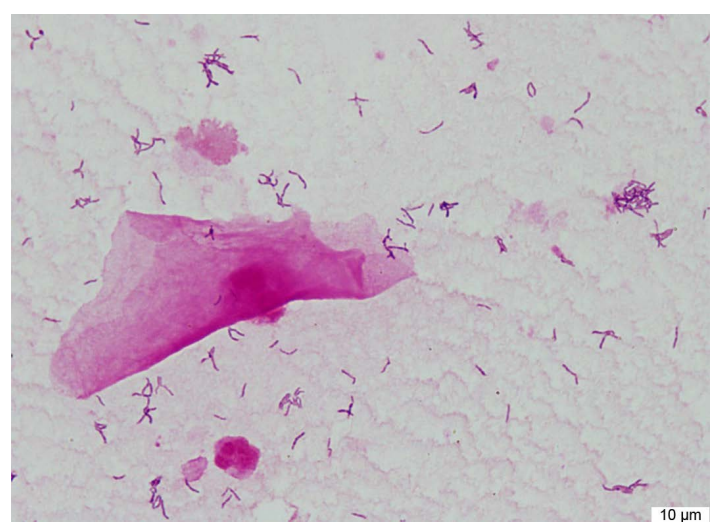

Figure 3. Gram-stained vaginal smear from the pregnant woman of case 7 (shown in Table 1). There is only Bifidobacterium spp. at 7 weeks of gestation. This smear is called "Bifidobacterium type". 


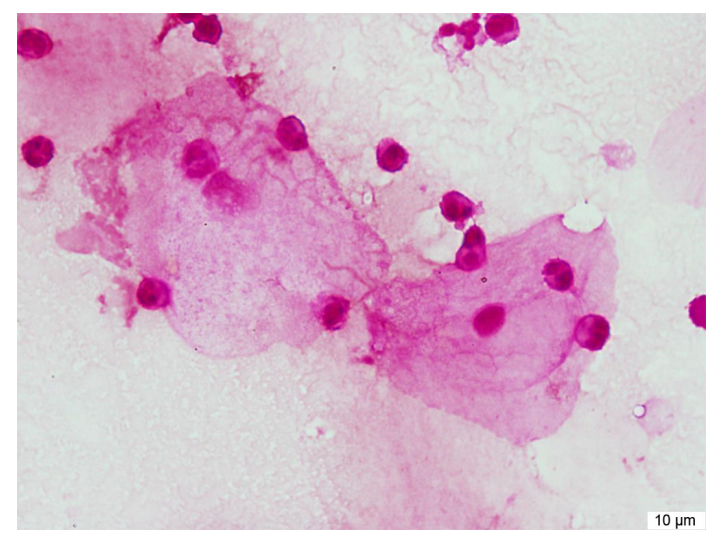

Figure 4. Gram-stained vaginal smear from the pregnant woman of case 14 who was transferred to our hospital as preterm PROM (shown in Table 1). There were no bacteria or epithelial cells at 24 weeks and 4 days of gestation. This smear is called "nonbacterial type".

1, Oil on the glass was washed out by $500 \mathrm{ul}$ absolute ethanol (FUJIFILM Wako
Pure Chemical).
2 , After the glass was dried, $50 \mathrm{uL}$ of MagNA Pure Bacteria Lysis Buffer (BLB,
Roche Life Science) was added to the sample on the glass and the sample
was scratched with the disposable micro-spatula.
3 , The BLB on the glass was collected into a new $1.5 \mathrm{ml}$ tube.
4 , To solubilize the bacteria, $90 \mathrm{uL}$ of BLB, $10 \mathrm{uL}$ of $10 \mathrm{x}$ DTT (Roche Life
Science) and $5 \mathrm{uL}$ of Enzyme Cocktail II (Roche Life Science) were added to
the tube, and the tube was incubated at 37 degrees C for 60 minutes.
5 , Additional lysis was conducted by heating ( 65 degrees C) with Proteinase K
(Roche Life Science).
6, The isolation of genomic DNA was done on a MagNA Pure 24 system (Roche
Life Science) using Pathogen 200 protocol.

Figure 5. Preparation of purified bacterial DNA from the Gram-stained vaginal smear. The bacterial DNA samples are collected from the Gram-stained vaginal smear on the glass according to the following procedure.

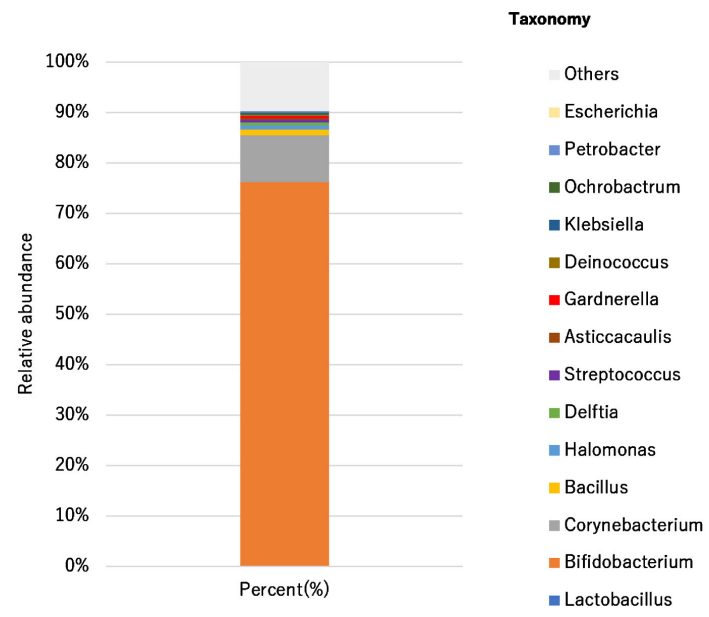

Figure 6. Result of the $16 \mathrm{~S}$ ribosomal RNA sequencing analysis of isolated DNA from the vaginal smear of case 7 (shown in Figure 3). This figure shows that the detected bacilli from case 7 were $B i$ fidobacterium spp. 
Table 1. The pregnant women with Nugent score 4 except for mixed type.

\begin{tabular}{|c|c|c|c|c|c|c|c|c|c|c|c|c|}
\hline Case & Age & Parity & Gravidity & $\begin{array}{l}\text { GW of } \\
\text { FV }\end{array}$ & PL & NS & GW of D & PB & FW (g) & $\begin{array}{l}\text { bacterial morphotypes } \\
\text { or culture }\end{array}$ & MT & note \\
\hline 1 & 39 & 0 & 1 & 10 & + & 4 & $41 \mathrm{w} 2 \mathrm{~d}$ & & 3240 & GBS & & penicillin + tocolytics \\
\hline 2 & 27 & 2 & 3 & 8 & + & 4 & $39 \mathrm{w} 2 \mathrm{~d}$ & & 3350 & GBS & & penicillin + tocolytics \\
\hline 3 & 25 & 0 & 0 & 18 & & 4 & $41 \mathrm{w} 2 \mathrm{~d}$ & & 3600 & Enterococcus sp. & & no therapy \\
\hline 4 & 35 & 0 & 0 & 31 & + & 4 & $33 \mathrm{w} 6 \mathrm{~d}$ & + & 1778 & Bifidobacterium $s p$. & + & fetal anomaly, polyhydramnios \\
\hline 5 & 36 & 0 & 0 & 21 & + & 4 & $36 \mathrm{w} 5 \mathrm{~d}$ & + & 2548 & Bifidobacterium sp. & + & ileus of mother \\
\hline 6 & 34 & 1 & 2 & 11 & & 4 & $37 \mathrm{w} 2 \mathrm{~d}$ & & 2734 & Bifidobacterium sp. & & metronidazole \\
\hline 7 & 31 & 1 & 1 & 7 & & 4 & $39 \mathrm{w} 0 \mathrm{~d}$ & & 2776 & Bifidobacterium sp. & & no therapy \\
\hline 8 & 27 & 2 & 2 & 7 & + & 4 & $37 \mathrm{w} 0 \mathrm{~d}$ & & 2892 & Bifidobacterium sp. & & metronidazole \\
\hline 9 & 35 & 1 & 1 & 12 & & 4 & $39 w 4 d$ & & 3126 & Bifidobacterium $s p$. & & metronidazole \\
\hline 10 & 28 & 1 & 1 & 7 & & 4 & $39 \mathrm{w} 5 \mathrm{~d}$ & & 3194 & Bifidobacterium sp. & & no therapy \\
\hline 11 & 37 & 0 & 0 & 28 & & 4 & $40 \mathrm{w} 0 \mathrm{~d}$ & & 3108 & Bifidobacterium sp. & & no therapy \\
\hline 12 & 31 & 1 & 1 & 34 & & 4 & $40 w 1 d$ & & 2509 & Bifidobacterium sp. & & no therapy \\
\hline 13 & 27 & 0 & 1 & 36 & & 4 & $40 \mathrm{w} 5 \mathrm{~d}$ & & 2608 & Bifidobacterium sp. & & no therapy \\
\hline 14 & 24 & 0 & 1 & 23 & + & 4 & $24 \mathrm{w} 4 \mathrm{~d}$ & + & 622 & negative & + & $\begin{array}{l}\text { PROM, prophylactic } \\
\text { antibiotics + tocolytics }\end{array}$ \\
\hline 15 & 29 & 0 & 0 & 34 & + & 4 & $34 w 3 d$ & + & 2284 & negative & + & PROM, prophylactic antibiotics \\
\hline 16 & 30 & 1 & 1 & 35 & + & 4 & $35 \mathrm{w} 2 \mathrm{~d}$ & + & 2028 & negative & + & PROM, prophylactic antibiotics \\
\hline 17 & 28 & 0 & 0 & 35 & + & 4 & $35 \mathrm{w} 6 \mathrm{~d}$ & + & 1488 & negative & + & PROM, prophylactic antibiotics \\
\hline 18 & 35 & 0 & 0 & 36 & + & 4 & $36 w 6 d$ & + & 1955 & negative & + & $\begin{array}{l}\text { PROM + IUGR, prophylactic } \\
\text { antibiotics }\end{array}$ \\
\hline 19 & 28 & 1 & 2 & 34 & & 4 & $38 \mathrm{w} 4 \mathrm{~d}$ & & 3240 & negative & + & PROM, prophylactic antibiotics \\
\hline 20 & 35 & 1 & 1 & 27 & + & 4 & unclear & & unclear & negative & + & transferred to previous HP \\
\hline
\end{tabular}

GW: Gestational Week, FV: First Visit, PL: Preterm Labor, NS: Nugent Score, D: Delivery, PB: Preterm Birth, FW: Fetal Weight, MT: Maternal Transferred.

Japan (Figure 7), and has a population of approximately 120,000. The number of deliveries in the city is about 1000 per year.

\subsection{Ethics Statements}

This study was reviewed and approved by the Institutional Review Board of $\mathrm{KRCH}$ (18-06).

\section{Results}

\subsection{Rates of Four Classifications of Nugent Score of 4}

A total of 58 patients of the 566 cases had a Nugent score of 4 (Figure 8). Among these, there were 38 cases (65.5\%) of mixed-type, 3 cases $(5.2 \%)$ of gram-positive cocci type, 10 cases (17.2\%) of Bifidobacterium type, and 7 cases (12.1\%) of non-bacterial type (Figure 9 ).

There were 20 cases of other than mixed-type, and these are indicated in Table 1: The gestational week at the first prenatal visit, the clinical diagnosis, the 


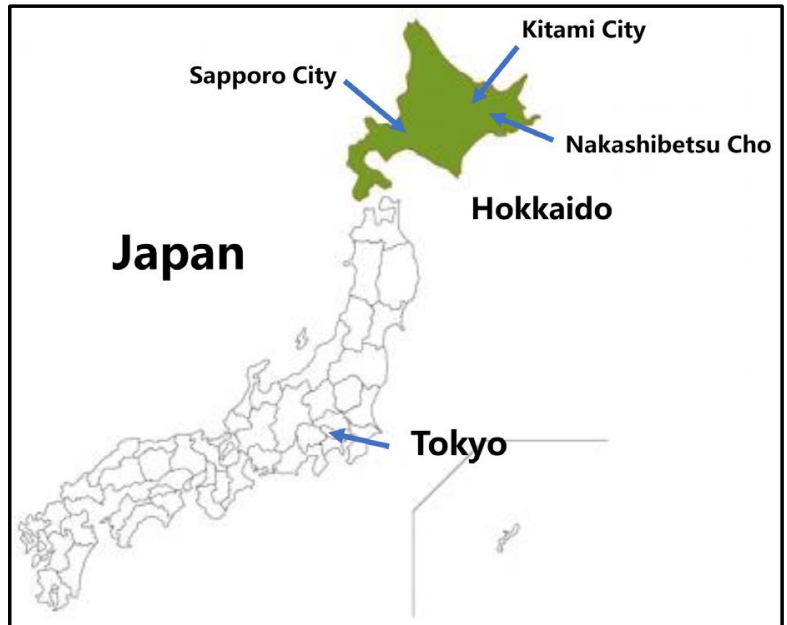

Figure 7. Kitami city is located in the eastern part of Hokkaido, the northern island of Japan.

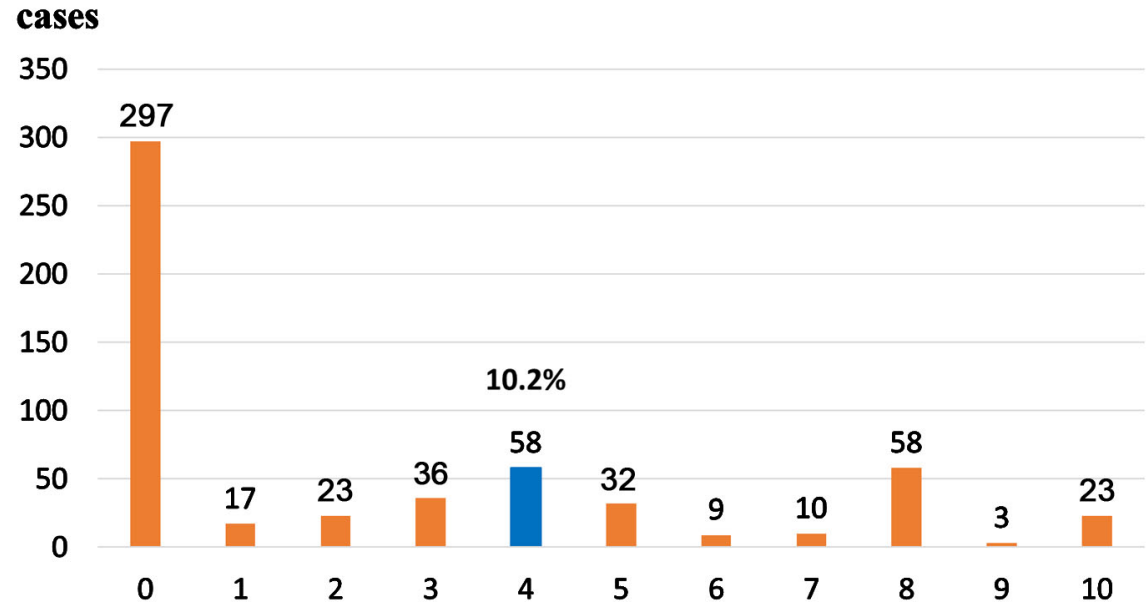

Figure 8. The distribution of Nugent scores for 566 cases.

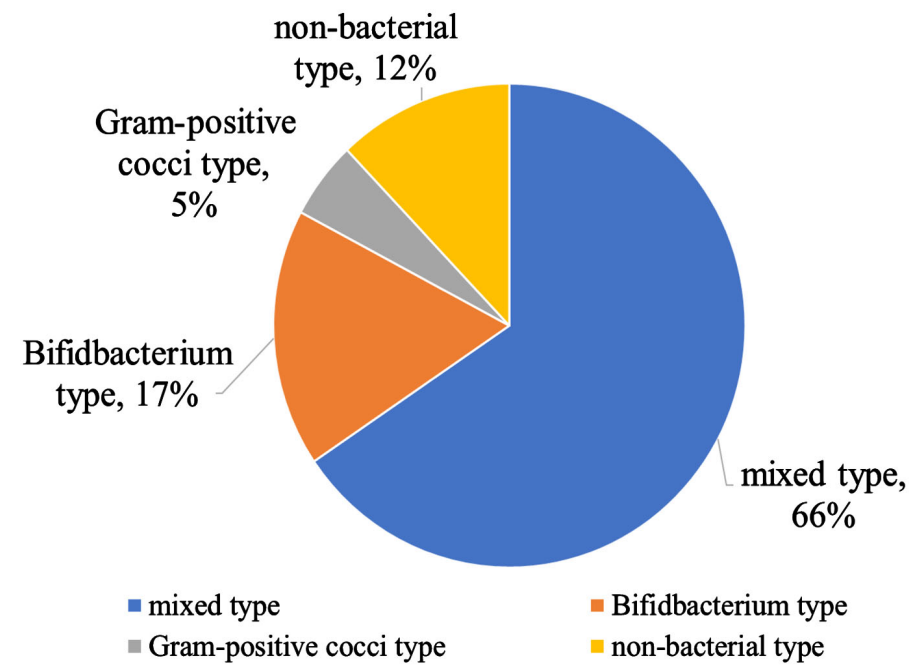

Figure 9. The distribution of four bacterial morphotypes for 58 cases with a Nugent score of 4 . 
results of the bacterial morphotypes and culture, prescribed antibiotics and tocolytics, medical history and pregnancy outcome.

\subsection{Pregnant Course and Outcome for Three Types of Nugent Score of 4}

In three gram-positive cocci type cases, two cases of GBS (cases 1,2) and one case of enterococcus spp. (case 3) were identified. There was a threatened preterm labor in the two cases that had the GBS (group B streptococcus) so we admitted them to hospital, prescribed penicillin and treated them with tocolytics. In one of the two cases, the lactobacillus started to appear after 5 weeks of therapy (Figure 10), and the GBS was present until delivery in week 41. All of the three cases resulted in term deliveries.

Case 4 resulted in preterm birth by polyhydramnios and fetal malformation, while case 5 resulted in preterm birth with maternal ileus. The clinician had administered metronidazole in three of eight cases of Bifidobacterium type because he misidentified them as mixed bacterial type. In all three cases, the Nugent score went down, and these cases resulted in term delivery. The other five cases of Bifidobacterium type resulted in term delivery with no therapy.

All of the seven pregnant women of non-bacterial type (Figure 4) were transferred to our hospital because they were suspected to be preterm PROM; Six of them were actually preterm PROM, and five of them experienced preterm birth despite prophylactic antibiotic therapy recommended in the 2017 Guidelines for Obstetrical Practice in Japan and obstetrics textbooks [11] [12]. In the last case, the pregnant woman was not diagnosed with preterm PROM at our hospital. Her vaginal bacterial flora was totally eradicated, because she had received antibiotic treatment as a potential preterm PROM patient at the previous hospital. She recovered fully and was retransferred to the previous hospital.

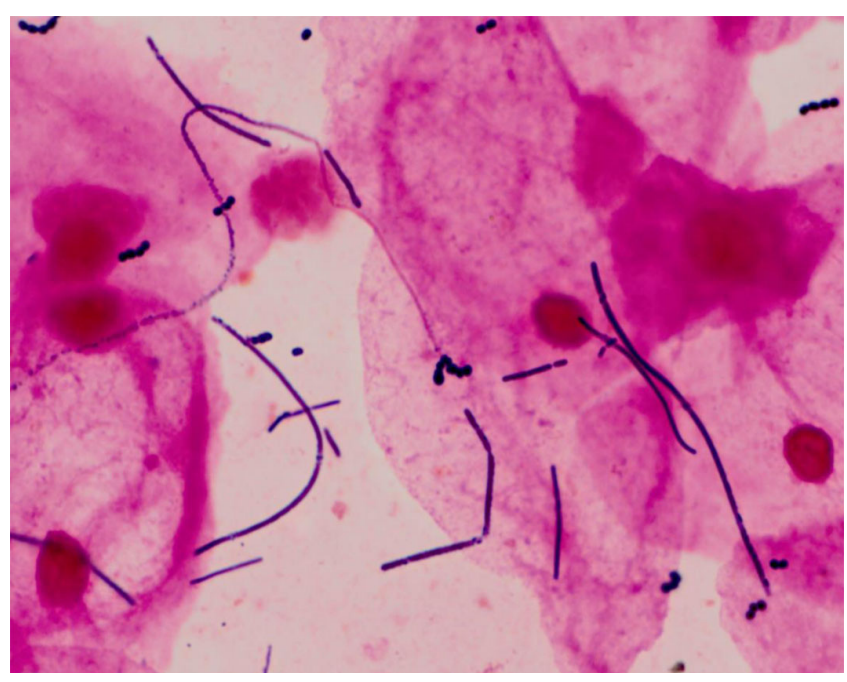

Figure 10. Gram-stained vaginal smear from the pregnant woman of case 1 (shown in Table 1). Gram-positive cocci and Lactobacillus morphotype were identified at 30 weeks of gestation. 


\section{Discussion}

We adopt the Nugent scoring system of gram-stained vaginal smears for the diagnosis of BV in our daily practice, with additional aerobic culture for the confirmation of bacteria including GBS and E. coli. Anaerobic culture is not performed in routine practice, based on Hillier's statement that "Cultures for G. vaginalis or other individual microbes have little utility for diagnosis of BV." [13] Thus, in this study, confirmation of Bifidobacterium spp., which are anaerobic bacteria, is based on the bacterial morphotype instead of anaerobic culture, except for the diagnosis in case 7 (Figure 3), in whom Bifidobacterium spp. was confirmed by the $16 \mathrm{~S}$ ribosomal RNA sequencing of DNA extracted from gram-stained smears taken eight years prior to this study (Figure 6). The results reported in this paper are based on the above conditions.

In the intermediate type, Nugent scores of 5 or 6 are almost the same as that of the mixed-type except for a smear with less than one or less than five gram-positive or -negative rods such as Gardnerella vaginalis or Bacteroides spp., respectively (Figure 11). These mixed-types are involved in BV and should be treated in order to prevent preterm birth, according to the reports by Ugwumadu [3] and Lamont [4]. However, we would like to point out that $34.5 \%$ of pregnant women with a Nugent Score of 4 are not all mixed-type. At least $22.4 \%$ of them are the gram-positive cocci type and Bifidobacterium type which should not be involved in BV. It may be necessary to have different kinds of treatment for each type of case.

Gram-positive cocci were excluded from the group of diagnostic bacteria in the Nugent Scoring system because there was poor agreement about their morphotype both within and between centers [8]. However, we thought that we could detect gram-positive cocci as long as these bacteria were present by

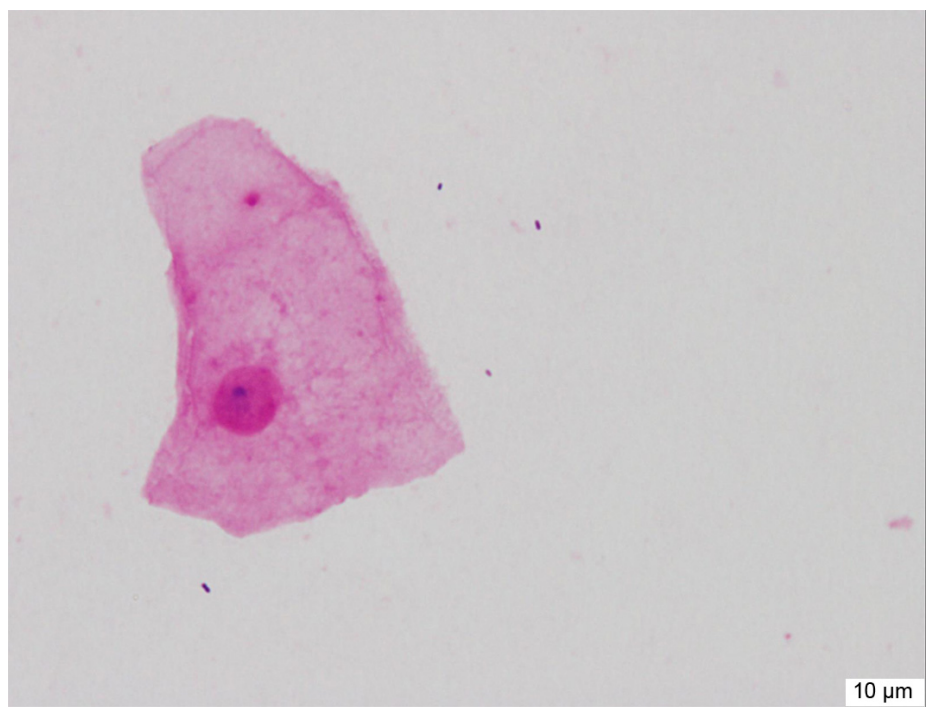

Figure 11. Gram-stained vaginal smear from the woman with a $\mathrm{Nu}$ gent score of 6. Four gram-negative rods like Gardnerella spp. or Bacteroides spp. morphotypes are present. 
themselves. Also, in two of the cases with the GBS vaginal flora, the patients suffered threatened preterm labor; they were prescribed penicillin and tocolytics, and their clinical course resulted in term delivery. It has been reported that GBS may directly invade the chorioamnion and cause chorioamnionitis [14] and that they could not be totally eradicated by penicillin administration [15]. If preterm labor symptoms appear, the physician should consider prescribing penicillin in order to prevent a secondary-bacterial infection in the uterus.

Pregnant women with the Bifidobacterium type were judged to require no treatment of their vaginal flora because Bifidobacterium spp. are generally regarded as non-pathogens except for Bifidobacterium dentium and members of the genera Bifidobacterium and Lactobacillus are considered health-promoting constituents of the gut microbiota and are mainly, but not exclusively, used as probiotic micro-organisms [16]. Especially Bifidobacterium bifidy and Bifidobacterium breve were present at higher concentrations and prevalence in the normal vagina than in the BV group, which may mean that they could be important for maintaining a healthy vaginal microenvironment [17]. In our study, there were five cases of Bifidobacterium type that resulted in term delivery with no therapy. Therefore, it may not be necessary to treat women carrying Bifidobacterium type for BV.

All of the pregnant women with a Nugent Score of 4 and a smear showing the non-bacterial type were transferred to the hospital during their mid or third trimester. Their vaginal flora was difficult to identify because their amniotic fluid had washed it out. We do not have information on whether the pregnant women presenting with mid- or third trimester preterm PROM had been screened for $\mathrm{BV}$ in their first trimester for the purpose of preventing preterm birth. We would like to emphasize the importance of screening for abnormal vaginal flora during the first prenatal visit in order to prevent and treat unexpected preterm PROM and threatened preterm labor. For reference, it has been reported that universal screening of pregnant women for BV is adopted in $67.1 \%(47 / 70)$ of facilities in Hokkaido [18].

\section{Limitations}

As the sample size in this study is limited, further investigation with an increased number of patients will be required. In particular, while pregnant patients with GBS and preterm PROM have been treated according to obstetrical textbooks, therapeutic approaches for Bifidobacterium spp. infections require further examination based on the study of more patients.

\section{Conclusion}

Among the pregnant women with a Nugent Score of 4, 34.4\% had gram-positive cocci type, Bifidobacterium type, or non-bacterial type smears. Women with gram-positive cocci type smears, in which the coccus has been identified as GBS, should be monitored for signs of threatened preterm birth due to ascending in- 
fection into the uterus from the vagina and be given penicillin in case of threatened preterm birth. Women with Bifidobacterium type smears should be monitored throughout the natural course of pregnancy as these bacteria are not pathogenic in pregnant women. Women with non-bacterial type smears should be suspected of PROM or that bacteria have been eradicated with antibiotic therapy. Thus, recording the presence of these three types of vaginal smears is considered necessary for later treatment decisions.

\section{Authorship Statement}

All authors meet the ICMJE authorship criteria.

\section{Disclosure}

This research did not receive any grants or financial support. Sample processing was done in Kitami Red Cross Hospital.

\section{Acknowledgements}

We are grateful to Dr. Kiyoshi Tyoji from the Nakashibetsu Municipal Hospital for his thoughtful suggestions and to Yoko Nagai from Varinos, Inc., Tokyo, Japan for the detection of Bifidobacterium spp. by $16 \mathrm{~S}$ ribosomal RNA gene sequencing (Figure 3, Figure 5 and Figure 6).

\section{Conflicts of Interest}

The authors declare no conflicts of interest regarding the publication of this paper.

\section{References}

[1] Brocklehurst, P., Gordon, A., Heatley, E. and Milan, S.J. (2013) Antibiotics for Treating Bacterial Vaginosis in Pregnancy. Cochrane Database of Systematic Reviews, No. 1, CD000262. https://doi.org/10.1002/14651858.CD000262.pub3

[2] Sangkomkamhang, U.S., Lumbiganon, P., Prasertcharoensuk, W. and Laopaiboon, M. (2015) Antenatal Lower Genital Tract Infection Screening and Treatment Programs for Preventing Preterm Delivery. Cochrane Database of Systematic Reviews, No. 2, CD006178. https://doi.org/10.1002/14651858.CD006178.pub3

[3] Ugwumadu, A., Manyonda, I., Reid, F. and Hay, P. (2003) Effect of Early Oral Clindamycin on Late Miscarriage and Preterm Delivery in Asymptomatic Women with Abnormal Vaginal Flora and Bacterial Vaginosis: A Randomized Controlled Trial. The Lancet, 361, 983-988. https://doi.org/10.1016/S0140-6736(03)12823-1

[4] Lamount, R.F., Duncan, S.L.B., Mandal, D. and Bassett, P. (2003) Intravaginal Clindamycin to Reduce Preterm Birth in Women with Abnormal Genital Tract Flora. Obstetrics \& Gynecology, 101, 516-522. https://doi.org/10.1016/S0029-7844(02)03054-5

[5] Shimano, S. and Komae, Y. (1995) Bacterial Vaginosis at the First Prenatal Visit and Pregnancy Outcome after Therapy. Japanese Journal of STI, 6, 103-110. http://sti.b-journal.net/journals/6-1/096-100.pdf

[6] Shimano, S., Nishikawa, A., Sonoda, T. and Kudo, R. (2004) Analysis of the Preva- 
lence of Bacterial Vaginosis and Chlamydia trachomatis Infection in 6083 Pregnant Women at a Hospital in Otaru, Japan. Journal of Obstetrics and Gynaecology Research, 30, 230-236. https://doi.org/10.1111/j.1447-0756.2004.00181.x

[7] Shimano, S., Tanaka, J. and Saito, T. (2017) Risk Factors for Bacterial Vaginosis during Pregnancy among Japanese Women in Hokkaido Nakashibetsu between 2011 and 2016. Japanese Journal of STI, 28, 101-109.

http://sti.b-journal.net/journals/28-1/101-109.pdf

[8] Nugent, R.P., Krohn, M.A. and Hillier, S.L. (1991) Reliability of Diagnosing Bacterial Vaginosis Is Improved by a Standardized Method of Gram Stain Interpretation. Journal of Clinical Microbiology, 29, 297-301. https://doi.org/10.1128/JCM.29.2.297-301.1991

[9] Cary, S.G. and Blair, E.B. (1964) New Transport Medium for Shipment of Clinical Specimens. Journal of Bacteriology, 88, 96-98.

https://doi.org/10.1128/JB.88.1.96-98.1964

[10] Kyono, K., Hashimoto, T., Nagai, Y. and Sakuraba, Y. (2018) Analysis of Endometrial Microbiota by $16 \mathrm{~S}$ Ribosomal RNA Gene Sequencing among Infertile Patients: A Single-Center Pilot Study. Reproductive Medicine and Biology, 17, 297-306. https://doi.org/10.1002/rmb2.12105

[11] Japan Society of Obstetrics and Gynecology (JSOG) and Japan Association of Obstetricians and Gynecologists (JAOG) (2017) Guidelines for Obstetrical Practice in Japan: 2017 Edition. 158-162. (In Japanese) https://doi.org/10.1111/jog.13831

[12] Cunningham, F.G., Levero, K.J., Bloom, S.L., et al. (2018) Williams Obstetrics. 25th Edition, McGraw-Hill, New York, 819-822.

[13] Hillier, S., Marrazzo, J. and Holmes, K.K. (2008) Bacterial Vaginosis. In: Holmes, K.K., Sparling, P.F., Stamm, W.E., et al., Eds., Sexually Transmitted Diseases, 4th Edition, McGraw-Hill, New York, 737-768.

[14] Hillier, S.L., Krohn, M.A., Kiviat, N.B., et al. (1991) Microbiologic Causes and Neonatal Outcomes Associated with Chorioamnion Infection. American Journal of $\mathrm{Ob}$ stetrics \& Gynecology, 165, 955-961. https://doi.org/10.1016/0002-9378(91)90447-Y

[15] Gardner, S.E., Yow, M.D., Lees, L.J., et al. (1979) Failure of Penicillin to Eradicate Group B Streptococcal Colonization in the Pregnant Women. American Journal of Obstetrics \& Gynecology, 135, 1062-1065. https://doi.org/10.1016/0002-9378(79)90737-3

[16] Biavati, B. and Mattarelli, P. (2012) Genus 1. Bifidobacterium Orla-Jensen 1924, $427^{\text {AL. }}$ In: Goodfellow, M., Kämpfer, P., Busse, H.-J., et al., Eds., Bergey’s Manual of Systematic Bacteriology, 2nd Edition, Volume 5, The Actinobacteria, Part A, Springer, New York, 184-185.

[17] Xia, Q., Cheng, L., Zhang, H., et al. (2016) Identification of Vaginal Bacteria Diversity and It's Association with Clinically Diagnosed Bacterial Vaginosis by Denaturing Gradient Gel Electrophoresis and Correspondence Analysis. Infection Genetics and Evolution, 44, 479-486. https://doi.org/10.1016/j.meegid.2016.08.001

[18] Shimano, S., Yamada, T., Sonoda, T., et al. (2016) Clinical Screening Strategies for Cervical Cancer, Chlamydia trachomatis Infection, and Bacterial Vaginosis in Pregnant Women in Hokkaido between 2004 and 2012: A Retrospective Study. International Journal of Women's Health Care, 1, 1-5. https://doi.org/10.33140/IJWHC/01/01/00003 